\title{
Travisia sanrikuensis, a New Species of Travisiidae (Annelida) from the Lower Bathyal Zone of the Northwestern Pacific
}

\author{
Genki Kobayashi ${ }^{1,4}$ and Shigeaki Kojima ${ }^{2,3}$ \\ ${ }^{1}$ Seto Marine Biological Laboratory, Field Science Education and Research Center, Kyoto University, \\ 459 Shirahama, Nishimuro, Wakayama 649-2211, Japan \\ E-mail: genkikobayashi5884@gmail.com \\ ${ }^{2}$ Atmosphere and Ocean Research Institute, The University of Tokyo, 5-1-5 Kashiwanoha, Kashiwa, Chiba 277-8564, Japan \\ ${ }^{3}$ Graduate School of Frontier Sciences, The University of Tokyo, 5-1-5 Kashiwanoha, Kashiwa, Chiba 277-8561, Japan \\ ${ }^{4}$ Corresponding author
}

(Received 2 October 2020; Accepted 29 December 2020)

http://zoobank.org/4D2FA859-2D08-4C16-8A3A-4D43E1A607F8

\begin{abstract}
A new species of the genus Travisia Johnson, 1840, the single genus of the family Travisiidae, is described. Specimens of Travisia sanrikuensis sp. nov. were collected in the Sanriku region, Japan, from the lower bathyal zone (871-1684 m depth) of the northwestern Pacific. Molecular phylogenetic analysis based on partial 16S rRNA gene sequences revealed that the new species is phylogenetically close to Travisia brevis Moore, 1923, but differs from all congeneric species by the following morphological characters: 25 segments, 20 chaetigers, and 19-20 pairs of cirriform branchiae starting from chaetiger 2.
\end{abstract}

Key Words: $16 \mathrm{~S}$ rRNA gene, deep sea, polychaete, Sedentaria, taxonomy.

\section{Introduction}

The family Travisiidae includes vermiform annelids within a single valid genus, Travisia Johnson, 1840, which comprises 36 described species (Wiklund et al. 2019; Blake and Maciolek 2020; Rizzo and Salazar-Vallejo 2020). Previously, Travisiidae was considered a subfamily of the family Opheliidae (Dauvin and Bellan 1994; Rouse 2001); however, subsequent molecular phylogenetic analyses indicated a close relationship between the species of Travisiidae and the family Scalibregmatidae (Persson and Pleijel 2005; Paul et al. 2010; Martínez et al. 2013, 2014; Law et al. 2014; Drennan et al. 2019). More recently, the subfamily status of Travisiidae has been re-evaluated and raised to the family level on the basis of morphological evidence (Blake and Maciolek 2020).

To date, at least seven described species and one subspecies of Travisia have been recorded from intertidal to hadal zones around the coastline of Japan: Travisia brevis Moore, 1923; Travisia forbesii Johnston, 1840; Travisia forbesii intermedia Annenkova, 1937; Travisia fusus (Chamberlin, 1919); Travisia glandulosa McIntosh, 1879 [as "Kesun abyssorum Monro, 1930" in Levenstein (1973)]; Travisia japonica Fujiwara, 1933; Travisia profundi Chamberlin, 1919; and Travisia pupa Moore, 1906 (Imajima and Hartman 1964; Levenstein 1970, 1973; Imajima 2001, 2009, 2011). During cruises undertaken as part of the Tohoku Ecosystem-associated Marine Sciences (TEAMS) research project, we collected specimens of Travisia from the lower bathyal zone of the northwestern Pacific off the Sanriku region (the northeastern part of Honshu Island), Japan (Fig. 1). In this study, we examined the morphology of the specimens, determined partial sequences of the 16S rRNA gene, and conducted phylogenetic analyses of Travisiidae. We describe these travisiid specimens as being new to science based on the results of these analyses.

\section{Materials and Methods}

Specimens were collected during the cruises of the research vessel (R/V) Shinsei-Maru in the northwestern Pacific off the Sanriku region of northeastern Japan (Fig. 1). Details of sampling are noted in Results and Discussion. The map of sampling localities was produced using Generic Mapping Tools (GMT) v5.1.1 (Wessel et al. 2013). All specimens were fixed and preserved in 70\% ethyl alcohol. The holotype and paratypes have been deposited in the National Museum of Nature and Science, Tsukuba (NSMT). The morphology of the specimens was examined and photographed under a stereomicroscope (Figs 2D-F, 3) and an entire specimen was photographed without the aid of a stereomicroscope (Fig. 2A-C). Furthermore, a single specimen (paratype NSMT-Pol P-831) was stained with methyl green solution to highlight the superficial morphology and characterize the staining pattern.

Portions of the body wall of the holotype, a paratype (NSMT-Pol P-828), and a non-type specimen (identifier GK627) were excised and treated with proteinase $\mathrm{K}$ solution (Nacalai Tesque) and then with $100 \mu \mathrm{L}$ of a $10 \%$ solution of Chelex 100 Resin (Bio-Rad) at $100^{\circ} \mathrm{C}$ for more than $20 \mathrm{~min}$. The resulting supernatant was used as template DNA.

Partial sequences of the mitochondrial 16S rRNA gene of the three specimens were determined by PCR using one or other of the following two reaction mixtures: (Mixture 


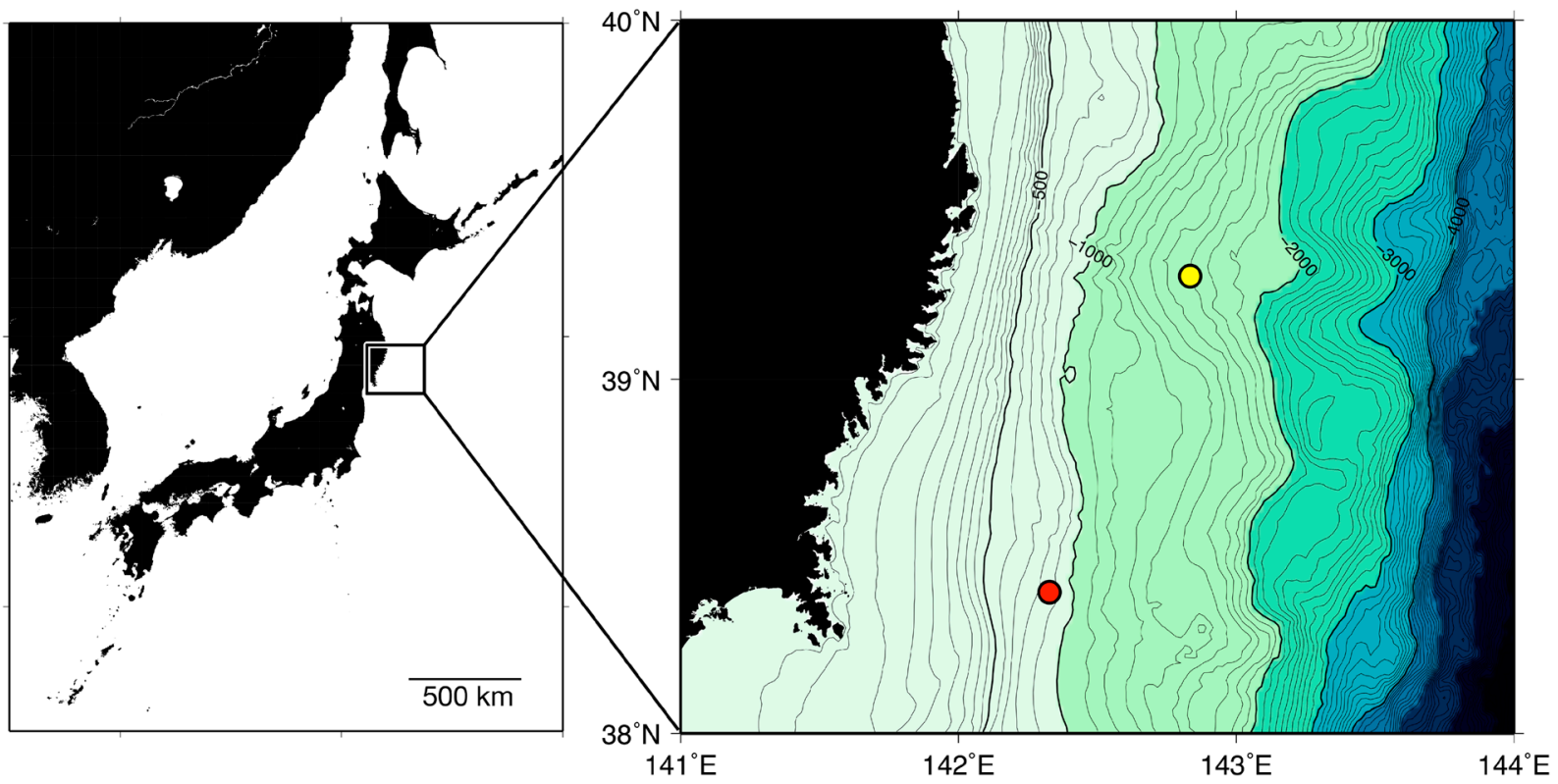

Fig. 1. Maps showing the sampling localities of Travisia sanrikuensis sp. nov. The red and yellow circles indicate the type locality and the sampling locality of a non-type specimen of T. sanrikuensis sp. nov., respectively.

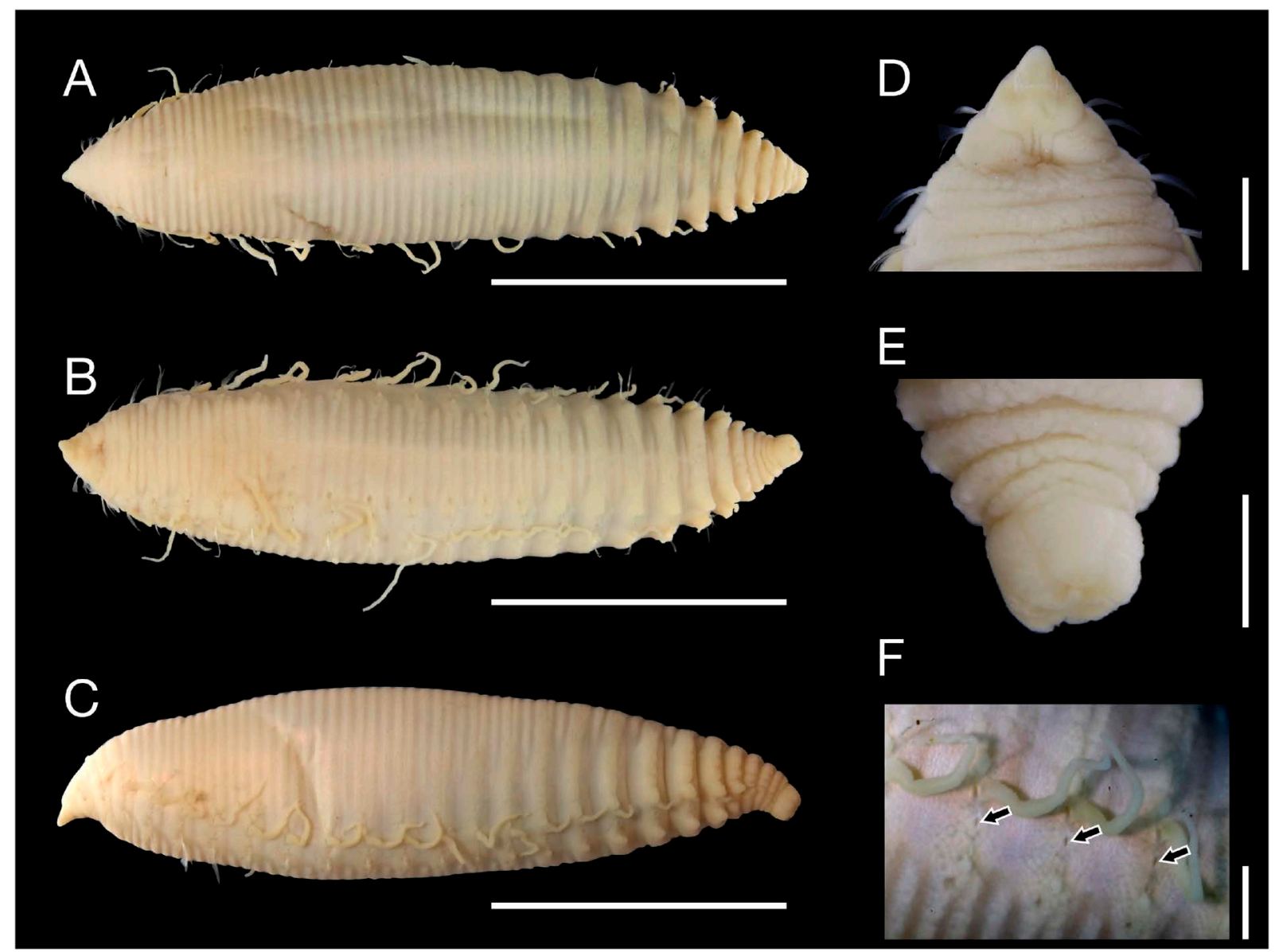

Fig. 2. Travisia sanrikuensis sp. nov. holotype (NSMT-Pol H-827). A, Dorsal view; B, ventral view; C, left lateral view; D, anterior end, ventral view; E, posterior end, ventral view; F, close-up view showing details of the lateral morphology. Arrows indicate interramal pores. Scale bars: $10 \mathrm{~mm}(\mathrm{~A}-\mathrm{C}) ; 1 \mathrm{~mm}(\mathrm{D}-\mathrm{F})$. 
1) $17.5 \mu \mathrm{L}$ of sterilized water, $0.13 \mu \mathrm{L}$ of TaKaRa Ex Taq Hot Start Version (TaKaRa Bio), $2.5 \mu \mathrm{L}$ of $10 \times$ Ex Taq Buffer, $2.0 \mu \mathrm{L}$ of $2.5 \mu \mathrm{M}$ dNTP mixture, $0.3 \mu \mathrm{L}$ of $20 \mu \mathrm{M}$ forward and reverse primers (Table 1), and $2.5 \mu \mathrm{L}$ of template DNA; (Mixture 2) $4.81 \mu \mathrm{L}$ of sterilized water, $0.25 \mu \mathrm{L}$ of MightyAmp DNA Polymerase Ver. 2 (TaKaRa Bio), $6.25 \mu \mathrm{L}$ of MightyAmp Buffer, $0.19 \mu \mathrm{L}$ of $20 \mu \mathrm{M}$ forward and reverse primers (Table 1), and $1.0 \mu \mathrm{L}$ of template DNA. PCR amplifications were performed using the following programs: (Mixture 1) initial denaturation at $94^{\circ} \mathrm{C}$ for $120 \mathrm{~s}$; followed by 35 cycles comprising denaturation at $94^{\circ} \mathrm{C}$ for $30 \mathrm{~s}$, annealing at $50^{\circ} \mathrm{C}$ for $40 \mathrm{~s}$, and extension at $72^{\circ} \mathrm{C}$ for $20 \mathrm{~s}$; and then a final extension at $72^{\circ} \mathrm{C}$ for $300 \mathrm{~s}$ or (Mixture 2) initial denaturation at $98^{\circ} \mathrm{C}$ for $120 \mathrm{~s}$; followed by 30 cycles of denaturation at $98^{\circ} \mathrm{C}$ for $10 \mathrm{~s}$, annealing at $50^{\circ} \mathrm{C}$ for $15 \mathrm{~s}$, and extension at $68^{\circ} \mathrm{C}$ for $20 \mathrm{~s}$. The PCR products thus obtained were purified using ExoSAP-IT (Thermo Fisher Scientific), and sequencing was performed either by using an $\mathrm{ABI}$ 3130xl automated DNA sequencer (Applied Biosystems,

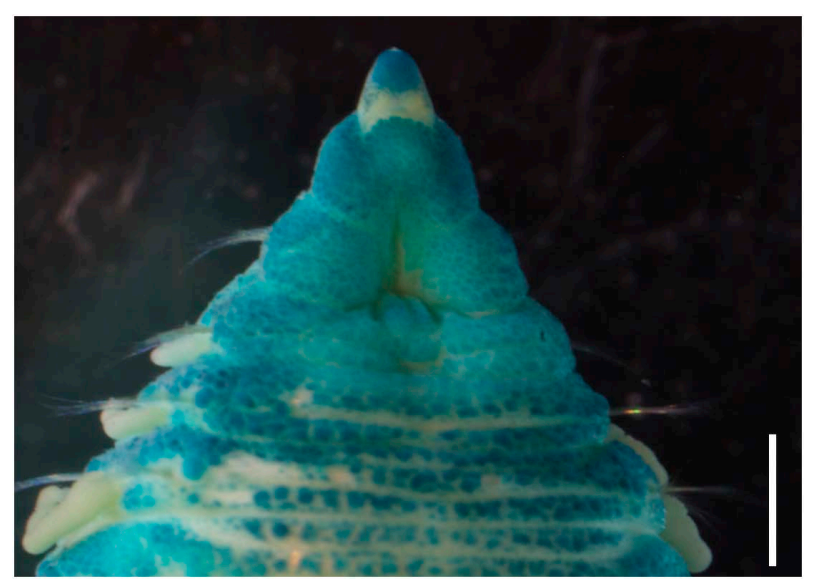

Fig. 3. Methyl green staining pattern on the prostomium of a Travisia sanrikuensis sp. nov. paratype (NSMT-Pol P-831), ventral view. Scale bar: $1 \mathrm{~mm}$.
ABI) or was outsourced to Eurofins Genomics. Prior to sequencing with the ABI sequencer, the PCR products were initially treated using a BigDye XTerminator Purification Kit (ABI) and a BigDye Terminator Cycle Sequence Kit v3.1 (ABI). The nucleotide sequences obtained have been deposited in the DNA Data Bank of Japan (DDBJ) with DDBJ/ EMBL/GenBank accession numbers LC566243 (holotype; 321 bp), LC566241 (paratype, NSMT-Pol P-828; 520 bp), and LC566242 (non-type specimen, GK627; $519 \mathrm{bp}$ ).

Phylogenetic analysis based on the 16S rRNA gene sequences was conducted using five travisiid and two scalibregmatid species to determine those species most closely related to the newly described species among those species registered in GenBank (Table 2). All nucleotide sequences except for those of the new species were obtained from the GenBank database. Alignment was performed using the MAFFT online service (Q-INS-i option, considering secondary structure) (Katoh et al. 2017). Ambiguous positions were deleted using Gblocks v0.91 (Castresana 2000) using default parameters, apart from the option "Allowed gap positions," which was set to "With half." For the purposes of this analysis, we used only a single sequence from one of our specimens (GK627), as the nucleotide sequences for all specimens were identical after trimming using Gblocks. The final dataset included 482 characters, and we selected the GTR + G model based on the Akaike information criterion (AIC) using JModelTest v2.1.10 (Darriba et al. 2012).

Molecular phylogenetic analyses using the 16S rRNA gene sequences were conducted using Bayesian inference and maximum likelihood (ML) methods. Bayesian analysis was performed using MrBayes v3.1.2 (Ronquist and Huelsenbeck 2003) with the setting "branch lengths unlinked." Two parallel runs were performed for 5 million generations (with a sampling frequency of 1000), using the default value of four Markov chains. The initial 25\% of samples were discarded and the subsequent $75 \%$ were accepted to ensure that the four chains reached stationary distributions, referring to the average standard deviation of split frequen-

Table 1. Nucleotide sequences of the primers for $16 \mathrm{~S}$ rRNA used in this study.

\begin{tabular}{lccc}
\hline Primer & Sequence $\left(5^{\prime}-3^{\prime}\right)$ & Direction $^{1}$ & Reference \\
\hline 16 SarL & CGCCTGTTTATCAAAAACAT & F & Palumbi (1996) \\
16 SbrH & CCGGTCTGAACTCAGATCACGT & R & Palumbi (1996) \\
16 Sann-f2 & CCTGACYGTGCWAAGGTAGC & F & R \\
16 Sann-r2 & CCYTAAGYCAACAYCGAGGT & This study \\
\hline
\end{tabular}

${ }^{1}$ Forward (F) or reverse (R).

Table 2. Species used in the phylogenetic analysis based on 16S rRNA gene sequences. The newly obtained sequence is shown in bold type.

\begin{tabular}{|c|c|c|c|}
\hline Family & Taxon & GenBank accession No. & References \\
\hline \multirow[t]{5}{*}{ Travisiidae } & Travisia sanrikuensis sp. nov. (GK627) & LC566242 & This study \\
\hline & Travisia brevis & HM746721 & Paul et al. (2010) \\
\hline & Travisia pupa & HM746722 & Paul et al. (2010) \\
\hline & Travisia sp. (NHM_1244) & MN217468 & Wiklund et al. (2019) \\
\hline & Travisia zieglerae & MN217490 & Wiklund et al. (2019) \\
\hline \multirow[t]{2}{*}{ Scalibregmatidae } & Polyphysia crassa & HM746719 & Paul et al. (2010) \\
\hline & Scalibregma inflatum & KF511816 & Law et al. (2014) \\
\hline
\end{tabular}


Table 3. Comparison of morphological characters of Travisia sanrikuensis sp. nov. and morphologically similar or genetically close species.

\begin{tabular}{|c|c|c|c|c|}
\hline & T. sanrikuensis sp. nov. ${ }^{1}$ & T. brevis ${ }^{2}$ & T. chiloensis $^{3}$ & T. oksae ${ }^{4}$ \\
\hline \multicolumn{5}{|l|}{ Number of } \\
\hline segments & 25 & 29 & 27 & $23-27$ \\
\hline chaetigers & 20 & $?$ & 24 & $20-25$ \\
\hline branchiae & $19-20$ & 22 & 20 & 22 \\
\hline first chaetiger with branchiae & 2 & $3^{5}$ & 2 & 2 \\
\hline posterior achaetous segments & 5 & $?$ & 3 & up to 3 \\
\hline
\end{tabular}

References: ${ }^{1}$ this study; ${ }^{2}$ Moore (1923); ${ }^{3}$ Kükenthal (1887); ${ }^{4}$ Hartmann-Schröder and Parker (1995); ${ }^{5}$ Rizzo and Salazar-Vallejo (2020).

cies (Ronquist and Huelsenbeck 2003). ML phylogenetic analysis was conducted using IQ-tree (Nguyen et al. 2014) based on 1000 ultrafast bootstrap replicates, and the resultant tree was edited using FigTree v1.4.3 (http://tree.bio. ed.ac.uk/software/figtree/).

\section{Taxonomy}

Family Travisiidae Hartmann-Schröder, 1971

Genus Travisia Johnston, 1840

Type species. Travisia forbesii Johnston, 1840.

\section{Travisia sanrikuensis sp. nov.}

(Figs 2, 3)

Type material. Holotype: (NSMT-Pol H-827), off Miyagi, Japan, the northwestern Pacific, the cruise KS-16-18 (R/V Shinsei-Maru), St. ON6, 11 November 2016, 871-880 m deep, $38^{\circ} 23^{\prime} 57^{\prime \prime}-22^{\prime} 58^{\prime \prime} \mathrm{N}, 142^{\circ} 20^{\prime} 05^{\prime \prime} \mathrm{E}$, collected using a $3 \mathrm{~m}$ beam trawl. Four paratypes: (NSMT-Pol P-828-P-831), from the same sample as the holotype.

Other material examined. Non-type specimen: off Otsuchi, Japan, the northwestern Pacific, the cruise KS-1712 (R/V Shinsei-Maru), St. Bent4, 3 October 2017, 1659$1684 \mathrm{~m}$ deep, $39^{\circ} 17^{\prime} 30^{\prime \prime}-18^{\prime} 18^{\prime \prime} \mathrm{N}, 142^{\circ} 48^{\prime} 25^{\prime \prime}-49^{\prime} 59^{\prime \prime} \mathrm{E}$, collected using a $3 \mathrm{~m}$ beam trawl, identifier GK627, 1 specimen.

Description. All type specimens complete. 18.9-25.8 mm (holotype $24.6 \mathrm{~mm}$ ) in length and 5.0-6.4 (holotype $5.8 \mathrm{~mm}$ ) in width at widest segment, whitish in alcohol, without pigmentation (Fig. 2A-C). Epidermal papillae present, indistinctive without Methyl green staining (Fig. 3). All specimens with 25 segments; first 20 segments chaetigerous, last five achaetous. Achaetous segments less developed (Fig. 2E) except first achaetous segment in the posterior region of paratype (NSMT-Pol P-829). Prostomium conical, eyes absent, a pair of nuchal organs present as dorsolateral slits. Peristomium short restricted to the mouth; mouth ventral with folds (Fig. 2D). Parapodia biramous, no parapodial lamellae on chaetiger 1. Parapodial lappets developed from chaetiger 15 or 16 to end of body. Subsequent parapodia very small. All chaetae capillary, approximately 10-20 per ramus, most chaetae shorter than branchiae. Notopodial and neuropodial chaetal rami well separated. Transverse ridges projected on last 10-11 segments, but somewhat indistinct in relaxed specimens. Middle body triannulate, an-

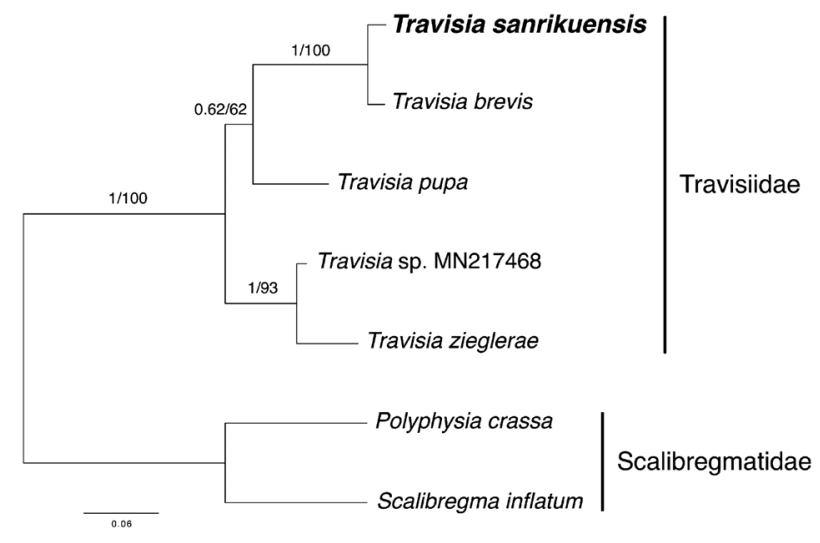

Fig. 4. Bayesian phylogeny of travisiid species based on $16 \mathrm{~S}$ rRNA gene sequences (482 characters). Numbers above branches indicate posterior probability followed by percentage maximum likelihood bootstrap values greater than 50\%. Travisia sanrikuensis sp. nov. is shown in bold type.

teriorly and posteriorly less annulated (biannulate or not annulated). Annulation in lateral body indistinctive. Branchiae cirriform from chaetiger 2 (19 pairs) except for paratype (NSMT-Pol P-829) with 20 branchiae, the last one short. Branchiae just posterior to notochaetae, long on middle chaetigers, short on first 3-4 chaetigers and most posterior chaetigers. Interramal pores, present on all chaetigers, posterior ones indistinct (Fig. 2F). Mid-ventral groove absent. Pygidium with shallow incisions, resulting in about 8 lobes around terminal anus (Fig. 2E). Methyl green staining pattern not characteristic in entire body, except white band (non-staining) on prostomium (Fig. 3)

Type locality. Off Miyagi, the Sanriku region, Japan, 871$880 \mathrm{~m}$ deep.

Etymology. The specific epithet sanrikuensis refers to the Sanriku region, encompassing the three prefectures Aomori, Iwate, and Miyagi, in the northeastern part of Japan, from where the specimens were collected, with the Latin suffixensis.

Remarks. Travisia sanrikuensis sp. nov. morphologically resembles Travisia chiloensis Kükenthal, 1887 and Travisia oksae Hartmann-Schröder and Parker, 1995, based on the taxonomic key presented by Rizzo and Salazar-Vallejo (2020). However, there are certain differences between $T$. sanrikuensis sp. nov. and these two species with respect to the number of segments, chaetigers, branchiae, and achaetous segments [note that achaetous segments in the posterior region of Travisia are regarded as annulations of the 
pygidium by Maciolek and Blake (2006)] (Table 3): 25 segments in T. sanrikuensis sp. nov. versus 27 in T. chiloensis; 20 chaetigers in T. sanrikuensis sp. nov. but 24 in T. chiloensis; 5 posterior achaetous segments in T. sanrikuensis sp. nov. although 3 or less in T. oksae; and 19 or 20 pairs of branchiae in T. sanrikuensis sp. nov. compared with 22 pairs in T. oksae. In addition, these three species show notable differences in bathymetric and/or geographic distribution: T. sanrikuensis sp. nov. inhabits sea beds in Japanese waters at depths from 871 to $1684 \mathrm{~m}$, whereas T. chiloensis is described from Chile [water depth unavailable from Kükenthal (1887)] and T. oksae is described from South Australia at depths of up to $18 \mathrm{~m}$ (Kükenthal 1887; HartmannSchröder and Parker 1995).

The results of phylogenetic analysis based on mitochondrial 16S rRNA gene sequences indicate that T. sanrikuensis sp. nov. is clustered with Travisia brevis (posterior probability =1.0, ML bootstrap value=100\%) (Fig. 4) collected from the eastern Pacific (Friday Harbor, WA) (Paul et al. 2010). However, the genetic difference between these two species is quite large $(3.4-3.7 \%, 11-12 \mathrm{bp}$ of $321 \mathrm{bp})$ compared with the variation among three specimens of T. sanrikuensis sp. nov. ( $<0.6 \%, \leq 2 \mathrm{bp}$ in $321 \mathrm{bp})$. T. sanrikuensis sp. nov. and T. brevis also differ in the following morphological characters (Table 3): the number of segments (25 in T. sanrikuensis sp. nov. vs. 29 in T. brevis) and branchiae (19 or 20 in T. sanrikuensis sp. nov. vs. 22 in T. brevis); branchiae starting from chaetiger 2 in T. sanrikuensis sp. nov. but from chaetiger 3 in T. brevis (Moore 1923; Rizzo and Salazar-Vallejo 2020). The numbers of branchiae and chaetigers have been established as key diagnostic characters for distinguishing travisiid species (Rizzo and Salazar-Vallejo 2020). Moreover, T. sanrikuensis sp. nov. and T. brevis differ with respect to bathymetric distribution, with T. sanrikuensis sp. nov. being collected from the lower bathyal zone (871-1684 $\mathrm{m}$ depths), whereas T. brevis was collected from the sublittoral zone (50-110 fathoms, i.e., 91-201 m depths in the eastern Pacific off San Diego, California) in the original description (Moore 1923). These results indicate that $T$. sanrikuensis sp. nov. differs sufficiently from $T$. brevis to be considered new to science.

The new species is distinguishable from all known travisiid species recorded from Japan by following characters: the smaller number of segments (25 in T. sanrikuensis sp. nov.) than T. brevis (29) (Moore 1923), T. japonica (39-40) (Fujiwara 1933), and in T. pupa (31-34) (Moore 1906; Imajima 2009); the numbers of chaetigers (20 in T. sanrikuensis sp. nov.) instead T. forbesii (23-26) (Dauvin and Bellan 1994), T. forbesii intermedia (26-29) (Annenkova 1937), T. fusus (28) (Chamberlin 1919), T. profundi (26) (Dauvin and Bellan 1994; Rizzo and Salazar-Vallejo 2020), and T. pupa (29) (Imajima 2009); and the number of branchiae (19-20 in $T$. sanrikuensis sp. nov.) from T. brevis (22) (Moore 1923), $T$. fusus (0) (Chamberlin 1919), T. glandulosa (0) (Dauvin and Bellan 1994), T. japonica (26) (Fujiwara 1933), and T. profundi (12) (Chamberlin 1919).

Distribution. Japan, the northwestern Pacific, in 871$1684 \mathrm{~m}$ deep.

\section{Acknowledgements}

We are grateful to Hajime Itoh, Mizuki Ohta, and Tsuyoshi Takano for supporting our field survey; the crew and researchers of the cruises KS-16-18 and KS-17-12 (R/V Shinsei-Maru); and the Principal Investigators Toshi Nagata and Kazuhiro Kogure for inviting authors on their research cruise. R/V Shinsei-Maru cruises were part of the research project Tohoku Ecosystem-Associated Marine Sciences (TEAMS) subsidized by the Ministry of Education, Culture, Sports, Science and Technology (MEXT). We also thank to Ryutaro Goto, Naoto Jimi, Nancy J. Maciolek, Takafumi Nakano, Masato Nitta, Satoshi Shimano, Hiroshi Yamasaki, and two anonymous reviewers for their invaluable comments on the earlier draft.

\section{References}

Annenkova, N. P. 1937. [Polychaete fauna of the northern part of the Japan Sea]. Issledovaniya fauny morei, Zoologicheskii Institut Akademii Nauk USSR Explorations des Mers de l'URSS 23: 139-216.

Blake, J. A. and Maciolek, N. J. 2020. Travisiidae Hartmann-Schröder, 1971, new family status. Pp. 302-311. In: Purschke, G., Böggemann, M., and Westheide, W. (Eds) Handbook of Zoology/Annelida, Volume 2: Pleistoannelida, Sedentaria II. De Gruyter, Berlin.

Castresana, J. 2000. Selection of conserved blocks from multiple alignments for their use in phylogenetic analysis. Molecular Biology and Evolution 17: 540-552.

Chamberlin, R. V. 1919. The Annelida Polychaeta [Albatross Expeditions]. Memoirs of the Museum of Comparative Zoology at Harvard College 48: 1-514.

Darriba, D., Taboada, G. L., Doallo, R., and Posada, D. 2012. jModelTest 2: more models, new heuristics and parallel computing. Nature Methods 9: 772.

Dauvin, J. C. and Bellan, G. 1994. Systematics, ecology and biogeographical relationships in the family Travisiinae (Polychaeta, Ophelidae). Mémoires du Muséum National d'Histoire Naturelle 162: 169-184.

Drennan, R., Wiklund, H., Rouse, G. W., Georgieva, M. N., Wu, X., Kobayashi, G., Yoshino, K., and Glover, A. G. 2019. Taxonomy and phylogeny of mud owls (Annelida: Sternaspidae), including a new synonymy and new records from the Southern Ocean, North East Atlantic Ocean and Pacific Ocean: challenges in morphological delimitation. Marine Biodiversity 49: 2659-2697.

Fujiwara, T. 1933. On a new species of Japanese Polychaeta, Travisia japonica sp. nov. Journal of Science of the Hiroshima University, Series B, Division 1 (Zoology) 2: 91-103.

Hartmann-Schröder, G. 1971. Annelida, Borstenwürmer, Polychaeta. Die Tierwelt Deutschlands 58: 1-594.

Hartmann-Schröder, G. and Parker, S. A. 1995. Four new species of the family Opheliidae (Polychaeta) from Southern Australia. Records of the South Australian Museum 28: 1-12.

Imajima, M. 2001. Deep-sea benthic polychaetous annelids of Tosa Bay, southwestern Japan. National Science Museum Monographs 20: 31-100.

Imajima, M. 2009. Deep-sea benthic polychaetes off Pacific coast of the northern Honshu, Japan. National Museum of Nature and Science Monographs 39: 39-192.

Imajima, M. 2011. Polychaetous annelids collected from Sagami Bay toward the Ogasawara Islands, Japan. Memories of the National Mu- 
seum of Natural Science of Tokyo 47: 145-218.

Imajima, M. and Hartman, O. 1964. The polychaetous annelids of Japan. Occasional Papers of the Allan Hancock Foundation 26: $1-452$.

Johnston, G. 1840. Miscellanea Zoologica. British Annelides. Annals and Magazine of Natural History 4: 368-375.

Katoh, K., Rozewicki, J., and Yamada, K. D. 2017. MAFFT online service: multiple sequence alignment, interactive sequence choice and visualization. Briefings in Bioinformatics 20: 1160-1166.

Kükenthal, W. 1887. Die Opheliaceen der Expedition der Vettore Pisani. Jenaische Zeitschrift für Naturwissenschaft 21: 361-373.

Law, C. J., Dorgan, K. M., and Rouse, G. W. 2014. Relating divergence in polychaete musculature to different burrowing behaviors: a study using Opheliidae (Annelida). Journal of Morphology 275: 548-571.

Levenstein, R. 1970. [Ecology and zoogeography of some representatives of the family Opheliidae (Polychaeta, Annelida) in the Pacific Ocean]. Trudy Instituta Okeanologii Akademiya Nauk SSSR 88: 213-226. [In Russian]

Levenstein, R. 1973. [A contribution to the polychaete fauna of the Aleutian, Japan and Izu-Bonin Trenches of the Pacific Ocean]. Trudy Instituta Okeanologii Akademiya Nauk SSSR 91: 128-135. [In Russian]

Maciolek, N. J. and Blake, J. A. 2006. Opheliidae (Polychaeta) collected by the R/V Hero and the USNS Eltanin cruises from the Southern Ocean and South America. Scientia Marina 70: 101-113.

Martínez, A., Di Domenico, M., and Worsaae, K. 2013. Evolution of cave Axiokebuita and Speleobregma (Scalibregmatidae, Annelida). Zoologica Scripta 42: 623-636.

Martínez, A., Di Domenico, M., and Worsaae, K. 2014. Gain of palps within a lineage of ancestrally burrowing annelids (Scalibregmatidae). Acta Zoologica 95: 421-429.

Moore, J. P. 1906. Additional new species of Polychaeta from the North Pacific. Proceedings of the Academy of Natural Sciences of Philadelphia 58: 217-260.
Moore, J. P. 1923. The polychaetous annelids dredged by the U.S.S. "Albatross" off the coast of southern California in 1904. IV. Spionidae to Sabellariidae. Proceedings of the Academy of Natural Sciences of Philadelphia 75: 179-259.

Nguyen, L. T., Schmidt, H. A., von Haeseler, A., and Minh, B. Q. 2014. IQ-TREE: a fast and effective stochastic algorithm for estimating maximum-likelihood phylogenies. Molecular Biology and Evolution 32: 268-274.

Palumbi, S. R. 1996. Nucleic acids II : the polymerase chain reaction. Pp. 205-247. In: Hillis, D.M., Mortiz, C., and Mable, B. K. (Eds) Molecular Systematics. Sinauer \& Associates Inc, Sunderland, MA.

Paul, C., Halanych, K. M., Tiedemann. R., and Bleidorn, C. 2010. Molecules reject an opheliid affinity for Travisia (Annelida). Systematics and Biodiversity 8: 507-512.

Persson, J. and Pleijel, F. 2005. On the phylogenetic relationships of Axiokebuita, Travisia and Scalibregmatidae (Polychaeta). Zootaxa 14: $1-14$.

Rizzo, A. and Salazar-Vallejo, S. I. 2020. A new species of Travisia (Annelida, Travisiidae) from Campos Basin, Brazil. Studies on Neotropical Fauna and Environment doi 10.1080/01650521. 2020.1752512 (7 May 2020).

Ronquist, F. and Huelsenbeck, J. P. 2003. MrBayes 3: Bayesian phylogenetic inference under mixed models. Bioinformatics 19: 15721574.

Rouse, G. 2001. Opheliidae Malmgren, 1867. Pp. 53-56. In: Rouse, G. and Pleijel, F. (Eds) Polychaetes. Oxford University Press, Oxford.

Wessel, P., Smith, W. H. F., Scharroo, R., Luis, J., and Wobbe, F. 2013. Generic Mapping Tools: improved version released. Eos, Transactions American Geophysical Union 94: 409-410.

Wiklund, H., Neal, L., Glover, A. G., Drennan, R., Rabone, M., and Dahlgren, T.G. 2019. Abyssal fauna of polymetallic nodule exploration areas, eastern Clarion-Clipperton Zone, central Pacific Ocean: Annelida: Capitellidae, Opheliidae, Scalibregmatidae, and Travisiidae. ZooKeys 883: 1-82. 